\title{
The impact of diurnal variations of air traffic on contrail radiative forcing
}

\author{
N. Stuber ${ }^{1}$ and P. Forster ${ }^{2}$ \\ ${ }^{1}$ Department of Meteorology, The University of Reading, Earley Gate, P.O. Box 243, Reading, Berkshire, RG6 6BB, UK \\ ${ }^{2}$ School of Earth and Environment, University of Leeds, Leeds, LS2 9JT, UK
}

Received: 3 August 2006 - Published in Atmos. Chem. Phys. Discuss.: 25 September 2006

Revised: 1 June 2007 - Accepted: 1 June 2007 - Published: 20 June 2007

\begin{abstract}
We combined high resolution aircraft flight data from the EU Fifth Framework Programme project AERO2k with analysis data from the ECMWF's integrated forecast system to calculate diurnally resolved 3-D contrail cover. We scaled the contrail cover in order to match observational data for the Bakan area (eastern-Atlantic/western-Europe).

We found that less than $40 \%$ of the global distance travelled by aircraft is due to flights during local night time. Yet, due to the cancellation of shortwave and longwave effects during daytime, night time flights contribute a disproportional $60 \%$ to the global annual mean forcing. Under clear sky conditions the night flights contribute even more disproportionally at $76 \%$. There are pronounced regional variations in night flying and the associated radiative forcing. Over parts of the North Atlantic flight corridor $75 \%$ of air traffic and $84 \%$ of the forcing occurs during local night, whereas only $35 \%$ of flights are during local night in South-East Asia, yet these contribute $68 \%$ of the radiative forcing. In general, regions with a significant local contrail radiative forcing are also regions for which night time flights amount to less than half of the daily total of flights. Therefore, neglecting diurnal variations in air traffic/contrail cover by assuming a diurnal mean contrail cover can over-estimate the global mean radiative forcing by up to $30 \%$.
\end{abstract}

\section{Introduction}

Aviation can affect climate through a number of mechanisms, both directly and indirectly. The most visible one, and possibly also the mechanism than can be managed most easily, is through contrails. A contrail will form when the atmospheric conditions at the aircraft's cruise altitude - in connection with the characteristics of the aircraft exhaust - are

Correspondence to: N. Stuber

(n.stuber@reading.ac.uk) favourable. Once formed, line-shaped contrails can persist for a few hours. Some of these persistent contrails can spread out and form cirrus clouds.

Whereas the climate effect (as measured by radiative forcing) of these contrail-induced cirrus clouds is highly uncertain, the radiative forcing due to line-shaped contrails is sufficiently known to be attributed at least a "fair" level of scientific understanding (IPCC, 1999). In its Special Report on Aviation IPCC (1999) gave a best estimate of global mean radiative forcing from line-shaped contrails in 1992 of $20 \mathrm{~mW} / \mathrm{m}^{2}$.

However, the IPCC estimate was based on a single study (Minnis et al., 1999), and since then the global radiative effects of contrails have been further investigated, using different datasets, models, and methods (e.g., Myhre and Stordal, 2001; Marquart et al., 2003; Fichter et al., 2005). However, it is worth noting that all these post-IPCC studies derived their contrail cover from applying the Sausen et al. (1998) method to observational or modelled temperature and humidity profiles. In these studies the estimate of global mean, annual mean radiative forcing due to line-shaped contrails has been continously lowered. In 2005 the TRADEOFF project updated the IPCC's 1992 value. Based on post-IPCC studies it gave $10.0 \mathrm{~mW} / \mathrm{m}^{2}$ as the best estimate of contrail radiative forcing in 2000 (Sausen et al., 2005).

In global studies of contrail radiative forcing the diurnal variation of air traffic is often neglected (e.g., Marquart et al., 2003; Fichter et al., 2005). Stuber et al. (2006) investigated the effects of diurnal variations of air traffic on contrail radiative forcing over south-east England. They found that flights during the night time have a disproportionate effect on the annual, diurnal mean contrail radiative forcing.

To determine the impact of diurnal variations of air traffic on global mean contrail radiative forcing, and to see how far the results of Stuber et al. (2006) are applicable to other regions and the globe, we performed a global calculation of the radiative forcing due to line-shaped contrails. We derived

Published by Copernicus Publications on behalf of the European Geosciences Union. 
Table 1. Top: Radiative forcing $\left[\mathrm{W} / \mathrm{m}^{2}\right]$ at the top of the atmosphere due to a $100 \%$ contrail cover $\left(\tau_{\text {vis }}=0.52\right)$ in a continental mid-latitude summer atmosphere. Bottom: Annual mean, global mean radiative forcings $\left[\mathrm{W} / \mathrm{m}^{2}\right]$ at the top of the atmosphere due to a $1 \%$ contrail cover $\left(\tau_{\mathrm{vis}}=0.3\right)$ for all-sky and clear sky conditions.

\begin{tabular}{lccc}
\hline & longwave & shortwave & net \\
\hline Meerkötter et al. (1999) & 51.5 & -22.0 & 29.5 \\
Myhre and Stordal (2001) & 45.6 & -25.2 & 20.4 \\
this study & 44.2 & -20.3 & 23.9 \\
\hline
\end{tabular}

\begin{tabular}{lrrrr}
\hline & \multicolumn{2}{c}{ MS2001 } & \multicolumn{2}{c}{ this study } \\
& all-sky & clear sky & all-sky & clear sky \\
\hline longwave & 0.21 & 0.27 & 0.19 & 0.25 \\
shortwave & -0.09 & -0.15 & -0.06 & -0.12 \\
net & 0.12 & 0.12 & 0.13 & 0.13 \\
\hline
\end{tabular}

contrail cover from a combination of diurnally resolved air traffic data, and ECMWF analysis data. This contrail cover data set has been derived independently from earlier studies and is used here for the first time. Contrail radiative forcing was calculated using the same sophisticated radiative transfer model as in Stuber et al. (2006).

\section{Model description}

We used the delta-4-stream version of the radiative transfer code of Fu and Liou (1992, 1993). The model includes gaseous absorption and scattering of shortwave as well as longwave radiation (Fu et al., 1997). For water clouds spherical droplets are assumed at all wavelengths. For ice clouds the optical properties in the longwave are computed using the method described in Fu et al. (1998), assuming randomly oriented hexagonal ice crystals. As well as taking part in model intercomparison exercises (Ellingson and Fouquart, 1990), the model has also been previously applied in cloud (e.g., Charlock et al., 1995; Carlin et al., 2002) and contrail studies (e.g., Meerkötter et al.,1999; Duda et al., 2001).

Solar insolation was modified according to the Julian day of the year. To account for the diurnal cycle of solar insolation we performed calculations every hour, varying the solar zenith angle accordingly. The sizes of the cloud or contrail particles were prescribed, letting the model calculate the liquid water content or ice water content needed to produce the prescribed optical depth in the visible $\left(\tau_{\mathrm{vis}}\right)$. Unless stated otherwise we assumed a contrail $\tau_{\text {vis }}$ of 0.1 . This value is in line with model simulations, which suggest a global mean contrail optical depth of about 0.1 (Marquart, 2003; M. Ponater, personal communication). Note that the value of 0.15 stated in Ponater et al. (2002; "On the global scale, mean contrail optical depth fluctuates around a value of 0.15 ...”) is actually the mean contrail optical depth at $250 \mathrm{hPa}$, as it refers to their Fig. 6, which shows contrail optical depth for this height only. We tested the sensitivity of our results to contrail optical depth by increasing $\tau_{\text {vis }}$ to 0.3 in an additional experiment.

Generalised effective diameters (Fu, 1996) of $55 \mu \mathrm{m}$ for high clouds and $10 \mu \mathrm{m}$ for mid and low clouds were assumed. The generalised effective diameter of the contrail particles was calculated from the particle spectrum given in Strauss et al. (1997), which is based on both in-situ measurements and a temperature dependent parametrisation.

To test our model configuration we repeated the calculations performed by Meerkötter et al. (1999) and Myhre and Stordal (2001; hereafter MS2001). Following Meerkötter et al. (1999), a $100 \%$ contrail cover with $\tau_{\text {vis }}=0.52$ was introduced into an otherwise clear atmosphere, using a continental midlatitude summer atmospheric profile. The contrail top was located as closely as possible to $11 \mathrm{~km}$.

Following MS2001 a $1 \%$ contrail cover $\left(\tau_{\mathrm{vis}}=0.3\right)$ was introduced globally at approximately $10.8 \mathrm{~km}$ altitude. Optical properties were prescribed according to Strauss et al. (1997). For this comparison we used seasonal mean atmospheric vertical profiles and surface data derived from a threedimensional climatology compiled at the University of Reading, in a 20 by 10 degrees longitude/latitude resolution. This climatology is based on satellite, aircraft and ground-based observations and provides long-term monthly mean profiles of temperature and the mixing ratios of water vapour and ozone on 15 to 19 vertical pressure levels extending up to $1 \mathrm{hPa}$. Information is also given about the surface albedo and the amount, optical depth and height of low, mid, and high level clouds. Cloud information is based on ISCCP C2 data (Rossow et al., 1988).

Given the different model configurations as well as differences inherent in a comparison, e.g., differences in clouds, temperature and humidity profiles, and surface albedo, the results (Table 1) agree reasonably well for both contrail configurations. This implies that once the amount, location and properties of line-shaped contrails are known, there is relatively little uncertainty in their radiative effect. It is worth noting, however, that all global estimates of contrail radiative forcing so far are based on calculations using a plane parallel geometry. Three-dimensional radiative transfer calculations have been found to increase the longwave radiative forcing and to either increase or decrease the shortwave radiative forcing - depending on the orientation of the contrail with respect to the sun (Gounou and Hogan, 2007). Although the individual effects are relatively small, they potentially have a significant impact on the fine balance between positive longwave and negative shortwave effects. However, until 3-D effects are incorporated to re-evaluate global contrail radiative forcing calculations, best estimates of global 
contrail radiative forcing have to be based on plane-parallel approximations.

\section{Air traffic and contrail cover}

We used gridded data from the EU FP5 project AERO2k (V1.0; see Eyers et al., 2004, for details) to calculate global contrail cover. This dataset records several aviation emissions and details of distances flown for each month in 2002 and for four six-hourly time periods - starting at midnight Greenwich Mean Time - averaged over one week in June 2002. The dataset gives a total fuel usage by civil aviation in 2002 of $156 \mathrm{Tg} / \mathrm{year}$. From the distance-flown data for June 2002, we calculated the maximum persistent contrail cover, assuming that every flight produced a contrail of a standard width and lifetime of $2 \mathrm{~km}$ and $2 \mathrm{~h}$, respectively. Both these values are reasonable choices for line-shaped, persistent contrails, according to both measurements and model simulations (Schumann, 1994; Gierens, 1996). Details of this methodology can be found in Stuber et al. (2006). However, as we later (see below) scaled the contrail cover to match mean contrail coverages obtained from satellite observations, these choices are not critical for the results.

The next step was to derive diurnally resolved data for each month. Ideally we would have liked to scale with the monthly air traffic at specific heights. Unfortunately this was not possible, as, for example, some layers which had air traffic in July had no air traffic in June. We therefore scaled June vertical distributions with the monthly total column air traffic for 2002. This has the consequence that while the total column amount of flights changes according to the time of year, the vertical profile of the percentage distribution of flights in specific heights is fixed to the June profile.

Next we calculated the contrail frequency of occurrence using analysis data of the European Centre for MediumRange Weather Forecasts' (ECMWF) integrated forecast system for the year 2004/2005. The data provides atmospheric profiles for each day of the month. We used data with a horizontal resolution of $2.5^{\circ}$ longitude/latitude. For each layer in each gridbox we determined whether conditions were favourable for the formation of a contrail by applying a temperature/humidity criterion. Contrails formed in a gridbox if the temperature was less than $233.16 \mathrm{~K}\left(-40.0^{\circ} \mathrm{C}\right)$ and the relative humidity with respect to ice exceeded $80.0 \%$. Sensitivity studies, comparing observations of contrails over Reading with ECMWF analysis data (for 2005) showed that these choices were the optimum thresholds for maximising the predictive success of the analysis data (Rädel and Shine, $2007^{1}$ ).

Note that in theory, instead of using a fixed optical depth, contrail optical depth could be calculated from the ECMWF

\footnotetext{
${ }^{1}$ Rädel, G. and Shine, K. P.: Influence of aircraft cruise altitudes on radiative forcing by persistent contrails, J. Geophys. Res., submitted, 2007.
}

data's humidity field. However, until very recently the ECMWF data did not carry ice supersaturation. This has now been changed (Tompkins et al., 2007), and in the future this method could now be a valuable tool to allow for variable contrail optical depths.

Multiplying the resulting contrail frequency of occurrence with the maximum possible contrail cover we obtained the actual vertical distribution of monthly mean contrail cover for each gridbox, for each of the four six-hour time periods. Note that due to having only one week of diurnally resolved AERO2k data we had to omit possible seasonal variations in the vertical distribution of air traffic (see above). Therefore, any seasonal variations in the height profile of contrails over a given location are solely due to variations in atmospheric conditions.

We scaled the data to match satellite observations for the eastern-Atlantic/western-Europe region. In 1992, the diurnal mean, annual mean contrail cover in this Bakan Area $\left(30^{\circ} \mathrm{W}-30^{\circ} \mathrm{E}, 35^{\circ} \mathrm{N}-75^{\circ} \mathrm{N}\right.$ ) amounted to $0.375 \%$ (Bakan et al., 1994; Marquart et al., 2003). This means that although flight data for 2002 was employed, by scaling the data we are effectively calculating the radiative forcing for 1992. This also implies implicitly assuming that a scaling for the Bakan area will also give "realistic" mean contrail covers in other parts of the world. Given the differences between different observational studies for the same area (e.g., Bakan et al., 1994; Meyer et al., 2002) these "realistic" values do not necessarily have to be consistent with observations. Indeed we find discrepancies, which are not unusual (cf., e.g., Marquart et al., 2003). For example, for Western Europe $\left(10^{\circ} \mathrm{W}-\right.$ $20^{\circ} \mathrm{E}, 40^{\circ} \mathrm{N}-55^{\circ} \mathrm{N}$ ) we calculate an annual, diurnal mean contrail cover of $0.9 \%$, which is higher than values obtained from observational data. Meyer et al. (2002) derived a value of $0.5 \%$, whereas the data given in Bakan et al. (1994) suggests a value of $0.7 \%$. Meyer et al. (2002) estimate the relative error of their data to vary between 50 and $100 \%$. Given the large error margins, observational and modeled contrail covers agree. However, the comparison clearly underlines the need for a systematic analyses of global contrail cover from observations.

To enable us to perform the calculations within a reasonable time-frame we reduced the spatial resolution to 20 by 10 degrees longitude/latitude by averaging the percentage contrail cover over the larger gridboxes.

As input for the radiative transfer calculations we derived vertical profiles of the atmosphere using the threedimensional climatology compiled at the University of Reading (see Sect. 2).

Figure 1 shows the annual variation in air traffic and global mean, monthly mean total column contrail cover, assuming random overlap of contrails in different layers. Global air traffic has a minimum in February and a maximum in August with the distance travelled by aircraft being approximately $23 \%$ larger. Nearly $94 \%$ of global air traffic are concentrated in the Northern Hemisphere, and an analysis of the AERO2k 


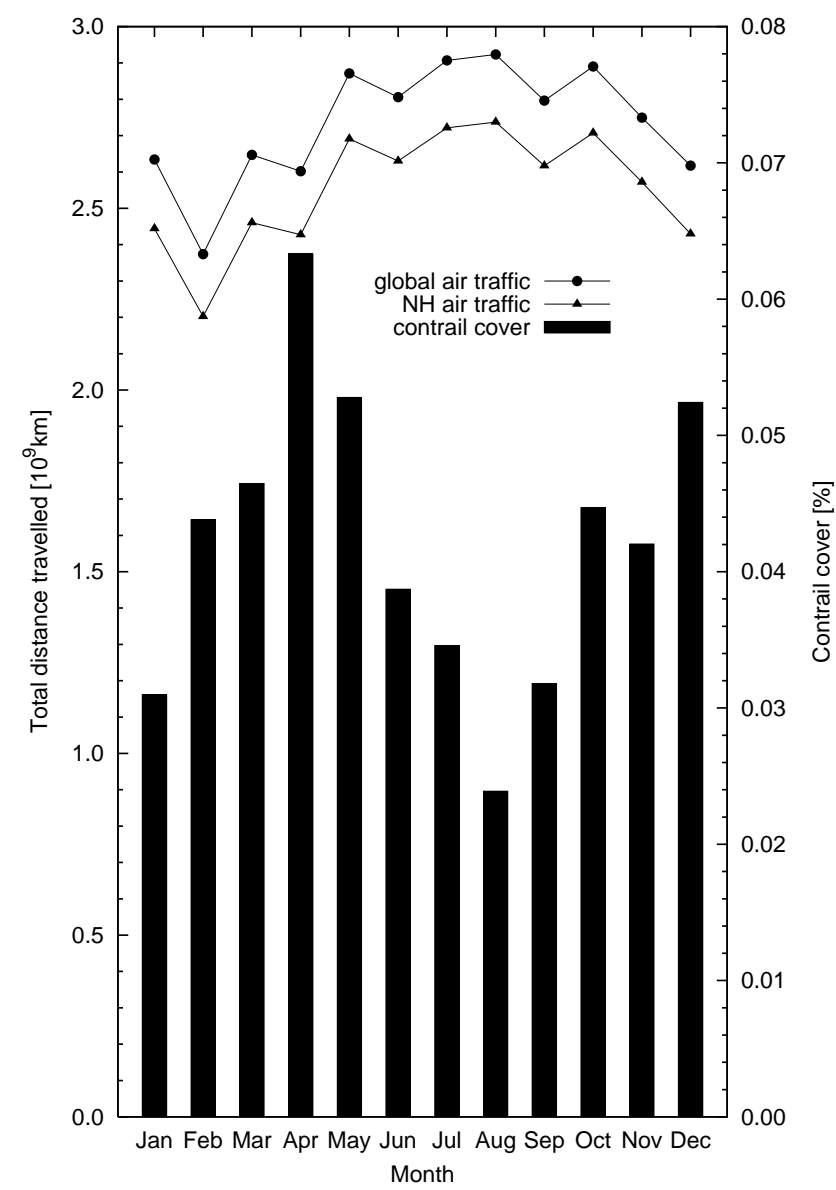

Fig. 1. Annual cycle of global and Northern Hemispheric air traffic (distance travelled in $10^{9} \mathrm{~km}$ ), and global mean, monthly mean contrail coverage (in \%).

data shows that traffic is especially dense in the North Atlantic flight corridor of northern mid-latitudes. This NH concentration of air traffic has very little seasonal variation.

The annual cycle in global mean, monthly mean contrail cover is affected by both, the amount of air traffic and the meteorological conditions which determine if flights will actually form contrails. Air traffic and contrail favourable conditions peak in different seasons. Whereas the global amount of air traffic is smallest in December, January, and February, chances for the formation of contrails reach a mimimum in June, July, and August, when the relative humidity in the upper troposphere of $\mathrm{NH}$ mid-latitudes has its lowest values (see, e.g., Kley et al., 2000). The annual variation in contrail cover shows that it is not the annual variations in air traffic, but rather the variations in contrail favourable conditions which have the dominant effect on the annual cycle in contrail coverage. (Global contrail coverage is smallest in Northern Hemispheric summer with a distinct minimum in August. This agrees with Marquart, 2003.) Assuming random overlap, the global mean, annual mean contrail cov-

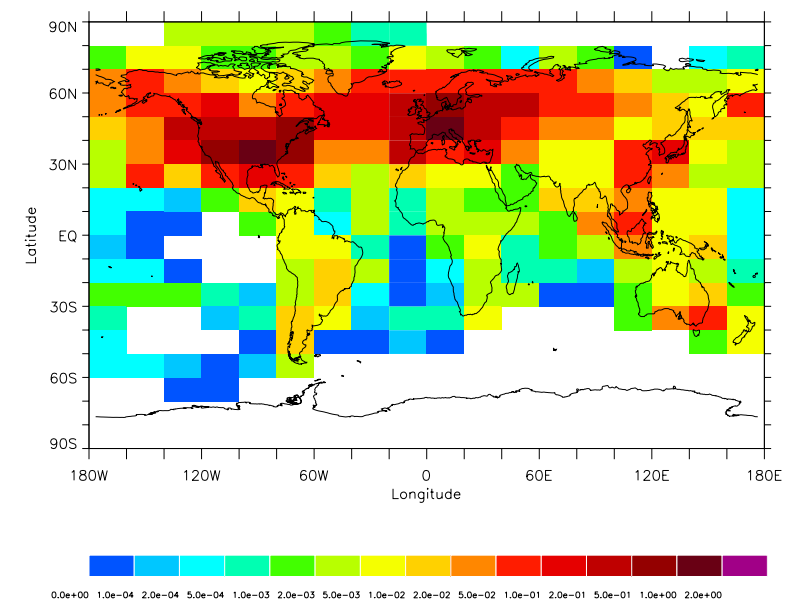

Fig. 2. Annual mean, diurnal mean contrail cover, in percent. Note the logarithmic scale.

Table 2. Global mean percentages of flights in the four 6-h AERO2k time periods and during night and daytime. Note that all times are local times.

\begin{tabular}{cccc}
\hline 00:00-06:00 & $06: 00-12: 00$ & $12: 00-18: 00$ & $18: 00-24: 00$ \\
\hline $14.6 \%$ & $31.1 \%$ & $33.1 \%$ & $21.2 \%$ \\
\hline
\end{tabular}

\begin{tabular}{cc}
\hline night & day \\
\hline $36.6 \%$ & $63.4 \%$ \\
\hline
\end{tabular}

erage, effective for 1992, is calculated to be $0.04 \%$. Both Marquart et al. (2003) and Fichter et al. (2005) used a GCM to determine contrail favourable conditions. Using flight data for 1992 they obtained global annual mean contrail covers of 0.06 and $0.047 \%$, respectively. Given the very different approach to calculating contrail cover, as well as differences in the flight data used, the agreement between the different estimates is encouraging.

The geographical distribution of total column contrail cover (Fig. 2) reflects the location of the major flight routings. However, the coarse horizontal resolution precludes detailed features from emerging. Maxima in contrail cover are seen over North America, the North Atlantic flight corridor, Europe, and the Far East.

Table 2 gives the global mean percentages of flights during the four six-hour time periods (times given are local times) as well as during local night and day time. We performed the calculations hourly in local time, determining the relevant contrail cover by converting local times into GMT. Contributions were calculated using the solar zenith angle as an 


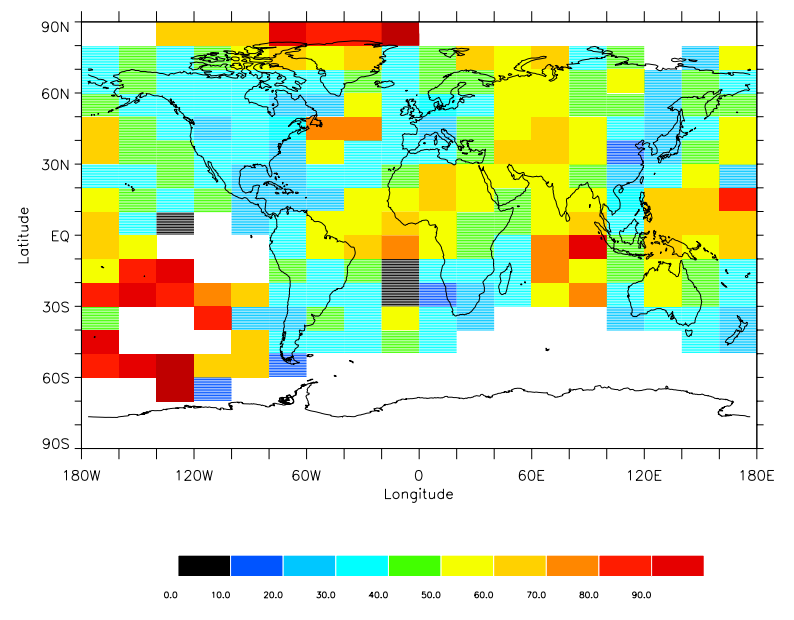

Fig. 3. Percentage of flights during local night time. Values higher than $50 \%$ are indicated by solidly filled boxes.

indicator of night and daytime. Note that in contrast to the numbers stated in Stuber et al. (2006), "night" and "day" are not approximated by the time periods 18:00-06:00 and 06:00-18:00, respectively, but refer to local times of daylight and darkness. Whereas the two time periods 06:0012:00 and 12:00-18:00 have approximately equal shares in daily total air traffic, air traffic is unequally distributed between local day and night time, and the distance travelled is split roughly 2 to 1 .

The diurnal variation in air traffic strongly depends on the geographic location (Fig. 3). For Western Europe and North America, where some night flying restrictions apply to both incoming and outgoing flights, night time flights typically amount to between 20 and $40 \%$ of the total amount of flights. This is in agreement with Meyer et al. (2002), who found a ratio of roughly 3 to 1 between daytime and night time contrail cover over Western Europe.

Flights heading for North America or Europe, where night flying restrictions are in place, have only certain time slots for departure from their home countries. Additionally, long haul flights, departing during day time, may well fly in darkness for parts of the journey. As a consequence, over parts of the Atlantic, Pacific, and Indian Ocean, as well as Asia, more than half of the daily total of air travel occurs during night time.

\section{Contrail radiative forcing}

We calculated a global, annual mean contrail radiative forcing of $2.0 \mathrm{~mW} / \mathrm{m}^{2}$ for 1992 all-sky conditions (Table 3, top). Night time flights contribute $60 \%$ of this forcing. During daytime, most (62\%) of the contrails' longwave effects are offset by their shortwave effects. If we assume clear sky conditions the forcing is slightly (5\%) larger (Table 3, bottom).

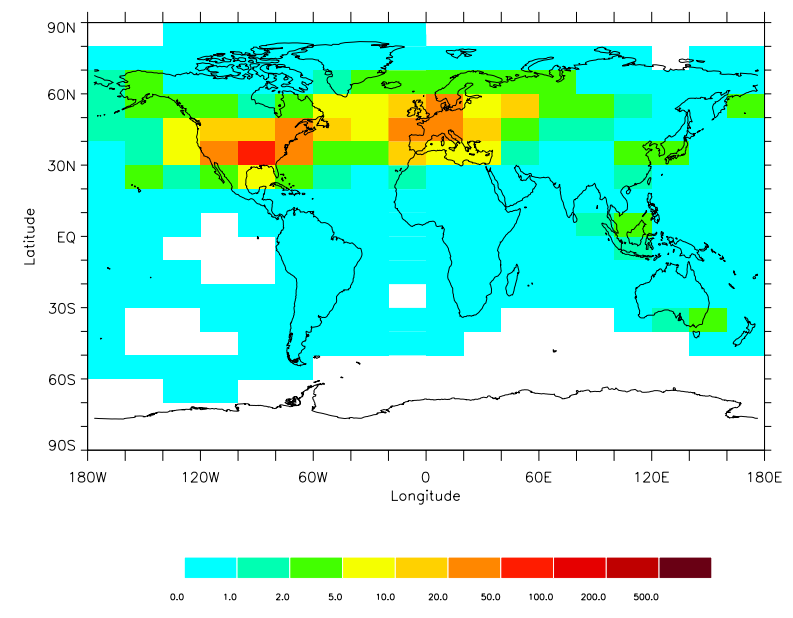

Fig. 4. Annual, diurnal mean net radiative forcing in $\mathrm{mW} / \mathrm{m}^{2}$, for all-sky conditions. Note the logarithmic scale.

This qualitatively agrees with results by Marquart (2003). The presence of natural clouds tends to reduce the magnitude of both the shortwave and longwave effects. Thus, they increase daytime net forcings, and reduce night time net forcings. In the absence of natural clouds the importance of night time flights is increased, with night time flights' contribution to the diurnal mean forcing amounting to $76 \%$. In this case the cancellation between longwave and shortwave effects during daytime is even more pronounced than for allsky conditions and amounts to $83 \%$.

The geographical distribution of the annual, diurnal mean net radiative forcing (Fig. 4) shows relative maxima of contrail radiative forcing over North America, Western Europe, and the North Atlantic flight corridor. With the exception of the North Atlantic flight corridor these are locations for which night time flights account for less than $50 \%$ of daily flights (Fig. 3).

Figure 5 shows a geographical distribution of the contribution of local night time flights to the annual, diurnal mean net radiative forcing. Over large parts of the globe night time flights contribute more than half of the annual, diurnal mean net radiative forcing. For two gridboxes in the southern $\mathrm{Pa}-$ cific the contributions are larger than $100 \%$. A close inspection of these gridboxes shows that air traffic and meteorological conditions are such that contrails only occur during one month, for which mean daytime forcings are negative. However, as Fig. 4 shows, the net forcing for these gridboxes is insignificant. Consistent with Fig. 3, for parts of the Atlantic, Pacific, and Indian Ocean, as well as Asia, where more than half of the daily total of air travel occurs during night time, up to $80 \%$ or more of the radiative forcing is due to night time flights. However, and in addition to these locations, in others where night flights only account for 20-30\% of flights (e.g., Central Europe), more than $60 \%$ of the radiative forcing can be attributed to night flights. 
Table 3. Global, annual mean longwave (lw), shortwave (sw), and net radiative forcing for all-sky (top) and clear sky (bottom) conditions in $\mathrm{mW} / \mathrm{m}^{2}$ for the four six-hour time periods (local time), as well as diurnal, night time and daytime means.

\begin{tabular}{lrrrrrrr}
\hline & & all-sky & & & & \\
& $00: 00-06: 00$ & $06: 00-12: 00$ & $12: 00-18: 00$ & $18: 00-24: 00$ & mean & night & day \\
\hline $\mathrm{lw}$ & 1.89 & 4.18 & 4.46 & 2.84 & 3.34 & 2.35 & 4.30 \\
$\mathrm{Sw}$ & -0.05 & -2.39 & -2.72 & -0.25 & -1.35 & 0.00 & -2.69 \\
$\mathrm{net}$ & 1.84 & 1.79 & 1.74 & 2.58 & 1.99 & 2.35 & 1.61 \\
\hline
\end{tabular}

\begin{tabular}{lrrrrrrr}
\hline & & \multicolumn{7}{c}{ clear sky } & & & \\
& $00: 00-06: 00$ & $06: 00-12: 00$ & $12: 00-18: 00$ & $18: 00-24: 00$ & mean & night & day \\
\hline $\mathrm{lw}$ & 2.55 & 5.68 & 6.05 & 3.86 & 4.54 & 3.22 & 5.85 \\
$\mathrm{sw}$ & -0.10 & -4.25 & -4.73 & -0.48 & -2.39 & 0.00 & -4.85 \\
$\mathrm{net}$ & 2.45 & 1.43 & 1.32 & 3.38 & 2.14 & 3.22 & 1.00 \\
\hline
\end{tabular}

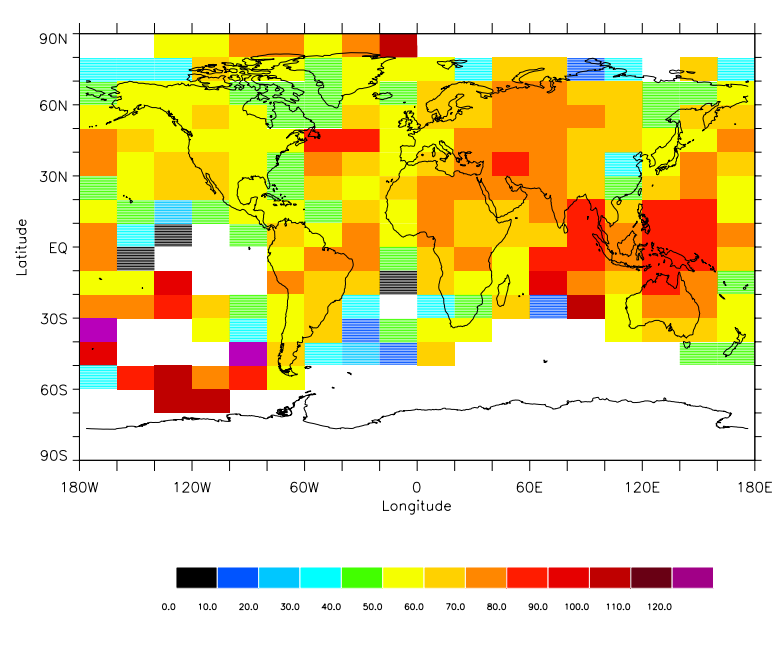

Fig. 5. Percentage contribution of flights during local night time to the annual mean diurnal mean contrail radiative forcing. Contributions less than $50 \%$ are indicated by striped boxes, contributions higher than $50 \%$ by solidly filled boxes.

In order to illustrate these points, Table 4 gives areamean percentages of night time flights and the associated radiative forcing for locations at the eastern coast of the US ("EUSA": $80^{\circ} \mathrm{W}-60^{\circ} \mathrm{W}, 40^{\circ} \mathrm{N}-50^{\circ} \mathrm{N}$ ), in the North Atlantic flight corridor ("NAFC-North": $40^{\circ} \mathrm{W}-20^{\circ} \mathrm{W}, 50^{\circ} \mathrm{N}-$ $60^{\circ} \mathrm{N}$; "NAFC-South": $40^{\circ} \mathrm{W}-20^{\circ} \mathrm{W}, 40^{\circ} \mathrm{N}-50^{\circ} \mathrm{N}$ ), SouthEast Asia ("SEA": $100^{\circ} \mathrm{E}-120^{\circ} \mathrm{E}, 10^{\circ} \mathrm{N}-20^{\circ} \mathrm{N}$ ), and Indonesia ("INDO": $120^{\circ} \mathrm{E}-140^{\circ} \mathrm{E}, 10^{\circ} \mathrm{S}-0^{\circ} \mathrm{N}$ ).

In order to determine the impact of the diurnal variation of air traffic on contrail radiative forcing, we conducted an additional experiment, in which we eliminated the diurnal variation by assuming the diurnal mean vertical profile of contrail cover at all times of day. Note that, as the vertical profile of air traffic is varying during the course of the day, assuming a diurnal mean contrail cover will change not only the amount but also the vertical distribution of contrails.

In the global, annual mean, eliminating the diurnal variation of air traffic increases the amount of flights during local night time (Table 2). Accordingly, the magnitude of the shortwave forcing decreases by about $17 \%$ (Table 5). The longwave forcing slightly increases by $5 \%$. As it is hardly affected by the solar zenith angle, the change in longwave forcing is likely to be due to changes in the vertical profiles of contrail cover. Depending on whether all-sky or clear sky conditions are assumed net radiative forcing increases by $20 \%$ (all-sky) to $30 \%$ (clear sky) when a diurnally constant contrail cover is imposed.

Figure 6 shows a geographic distribution of the annual mean relative underestimation or overestimation of contrail radiative forcing that results from omitting the diurnal variation of air traffic. For those locations with a significant local forcing (cp., Fig. 4), i.e., the USA, Western Europe, and large parts of the North Atlantic flight corridor, net radiative forcings are overestimated when the diurnal variation of air traffic is neglected. For these locations a diurnally uniform distribution of flights increases the amount of flights during local night time (Fig. 3), and thus decreases the amount of cancellation between longwave and shortwave effects, resulting in an increase of the net forcing.

\section{Discussion and conclusions}

Combining AERO2k flight data with analysis data from the ECMWF's integrated forecast system, and calibrating for the 1992 contrail cover in the Bakan Area, we calculated a diurnally resolved 3-D distribution of contrail cover. We 
Table 4. Area-mean percentages of flights during local night time, and the percentage of annual mean, diurnal mean radiative forcing due to these flights, for the eastern coast of the U.S. (EUSA), the northern and southern part of the North Atlantic flight corridor (NAFC-North; NAFC-South), South-East Asia (SEA), and Indonesia (INDO). See text for details of the geographic locations.

\begin{tabular}{lccccc}
\hline & EUSA & NAFC-North & NAFC-South & SEA & INDO \\
\hline percentage flights & 34.2 & 52.4 & 74.8 & 34.5 & 61.2 \\
percentage RF & 53.7 & 64.0 & 84.1 & 68.0 & 83.3 \\
\hline
\end{tabular}

Table 5. Global, annual and diurnal mean longwave, shortwave, and net radiative forcings in $\mathrm{mW} / \mathrm{m}^{2}$, for both all-sky and clear sky conditions with or without diurnal variations of air traffic.

\begin{tabular}{lrr}
\hline & \multicolumn{2}{c}{ all-sky } \\
& with diurnal cycle & w/o diurnal cycle \\
\hline lw & 3.34 & 3.52 \\
Sw & -1.35 & -1.11 \\
net & 1.99 & 2.41 \\
\hline
\end{tabular}

\begin{tabular}{lrr}
\hline \multicolumn{3}{c}{ clear sky } \\
& with diurnal cycle & w/o diurnal cycle \\
\hline lw & 4.54 & 4.78 \\
Sw & -2.39 & -1.99 \\
net & 2.14 & 2.79 \\
\hline
\end{tabular}

calculated the radiative forcing for this contrail cover distribution, assuming a constant contrail optical depth.

Stuber et al. (2006) found that for the south-east of England night flights contribute 60 to $80 \%$ to the annual mean forcing, despite the fact of being responsible for only $25 \%$ of the flights. Globally, the amount of night flights is larger, with almost $40 \%$ of the total distance travelled being due to flying during local night time. Their contribution to the annual mean contrail radiative forcing is very similar to that for flights over south-east England. For all-sky conditions they contribute $60 \%$ to the annual mean contrail radiative forcing. For clear sky conditions their relative importance is even higher $(76 \%)$.

Table 6 compares the contrail radiative forcing obtained in this study with values from earlier studies, which have been obtained using approaches that were different and sometimes very different to our own. In order to still be able to compare the results, we have linearly scaled radiative forcing with globally averaged contrail cover. This method is only approximate, as illustrated by the results below. However, it provides the possibility of placing the results in the context of previous studies which used different methodologies and assumptions. In this respect it is useful to note that all

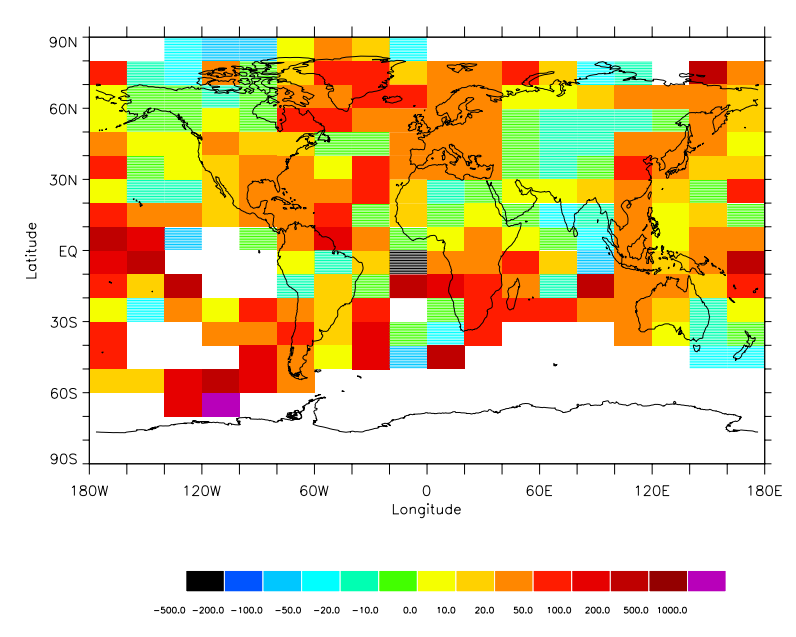

Fig. 6. Geographical distribution of the percentage overestimation/underestimation (positive/negative values) of annual mean contrail radiative forcing resulting from an omission of the diurnal cycle of air traffic. For easy access, positive values (overestimation) are marked with filled boxes, negative values (underestimation) with striped boxes, respectively. The global mean value is $+20 \%$.

these previous studies derived contrail cover from applying the method outlined in Sausen et al. (1998) - either to observed or to simulated atmospheric profiles.

Myhre and Stordal (2001; MS2001) used the Sausen et al. (1998) contrail cover, which is based on the DLR inventory (Schmitt and Brunner, 1997), to calculate global contrail radiative forcing. The global mean contrail cover for this data set amounts to $0.09 \%$, also for 1992 . They scaled the data to obtain a diurnally resolved contrail cover and used a radiative transfer model to calculate contrail radiative forcing. Assuming a contrail visible optical depth of 0.3 they calculated a net forcing of $9.0 \mathrm{~mW} / \mathrm{m}^{2}$. Typical global mean contrail optical depths are now believed to be lower than 0.3 (Ponater et al., 2002; Ponater, personal comunication). However, increasing the optical depth in our calculation to 0.3 results in a net radiative forcing of $5.0 \mathrm{~mW} / \mathrm{m}^{2}$. A linear scaling of this value for a global mean contrail cover of $0.09 \%$ increases the forcing to $11.3 \mathrm{~mW} / \mathrm{m}^{2}$, which is $25 \%$ larger than the equivalent value calculated by MS2001. One reason for this discrepancy is that the model used by MS2001 
Table 6. Comparison of contrail radiative forcing RF in 1992 (in $\mathrm{mW} / \mathrm{m}^{2}$ ) calculated in this study with results from earlier studies. "Scaled" indicates values that have been linearly scaled with contrail cover (in \%). For the two studies with a variable optical depth, the approximate global mean value of $\tau_{\text {vis }}$ is given.

\begin{tabular}{|c|c|c|c|c|}
\hline study & contrail cover & $\tau_{\mathrm{vis}}$ & $\begin{array}{l}\text { diurnal cycle } \\
\text { air traffic }\end{array}$ & $\mathrm{RF}$ \\
\hline this study & 0.04 & fixed, 0.1 & yes & 2.0 \\
\hline this study & 0.04 & fixed, 0.3 & yes & 5.0 \\
\hline MS2001 & 0.09 & fixed, 0.3 & yes & 9.0 \\
\hline this study, scaled & 0.09 & fixed, 0.3 & yes & 11.3 \\
\hline this study & 0.04 & fixed, 0.1 & no & 2.4 \\
\hline Marquart et al. (2003) & 0.06 & variable, 0.1 & no & 3.5 \\
\hline this study, scaled & 0.06 & fixed, 0.1 & no & 3.6 \\
\hline Fichter et al. (2005) & 0.047 & variable, 0.1 & no & 3.2 \\
\hline this study, scaled & 0.047 & fixed, 0.1 & no & 2.8 \\
\hline
\end{tabular}

Table 7. Contrail radiative forcing in $\mathrm{mW} / \mathrm{m}^{2}$ for different time horizons, obtained by a linear scaling with fuel usage. Fuel usage in 1992, 2000, and 2002 was 112,152 , and $156 \mathrm{Tg} /$ year, respectively. The TRADEOFF best estimate of $10 \mathrm{~mW} / \mathrm{m}^{2}$ for 2000 is based on scaled values from studies by MS2001 and Marquart et al. (2003), which are cited in this table. Note that the studies differ in the amount of contrail cover (see Table 6).

\begin{tabular}{lccc}
\hline study & year & $\tau_{\text {vis }}$ & RF \\
\hline this study & 1992 & fixed, 0.1 & 2.0 \\
MS2001 (TRADEOFF scaled) & 2000 & fixed, 0.3 & 15 \\
Marquart et al. (2003) (TRADEOFF scaled) & 2000 & variable, 0.1 & 6.0 \\
this study, scaled & 2000 & fixed, 0.1 & 2.7 \\
this study, scaled & 2000 & fixed, 0.3 & 6.8 \\
this study, scaled & 2002 & fixed, 0.1 & 2.8 \\
this study, scaled & 2002 & fixed, 0.3 & 7.0 \\
\hline
\end{tabular}

assumes non-scattering clouds in the longwave part of the spectrum. Scattering of longwave radiation is known to enhance the greenhouse effect of clouds and especially high clouds and contrails (e.g., Edwards and Slingo, 1996; Marquart and Mayer, 2002). Other reasons are most likely differences in the horizontal and vertical distribution of air traffic and, hence, contrails, the distribution of natural clouds, and differences in the background meteorological conditions.

Marquart et al. (2003) also adopted the DLR inventory, but used a GCM to determine both contrail cover and optical depth. They obtained a global, annual mean contrail cover of $0.06 \%$. The mean contrail optical depth is about 0.1 (Marquart, 2003; Table 3.3). Neglecting the diurnal cycle of air traffic, but correcting their result a posteriori for the effects of longwave scattering excluded in the GCM's radiation code, they calculated a contrail radiative forcing of $3.5 \mathrm{~mW} / \mathrm{m}^{2}$ for 1992. They stated that including the diurnal cycle of air traf- fic decreased their forcing by less than $10 \%$. Using the same GCM, but the inventory developed within the EU FP5 project TRADEOFF, Fichter et al. (2005) obtained a global annual mean contrail cover for 1992 of $0.047 \%$. Again neglecting the diurnal variation in air traffic, they calculated a contrail radiative forcing of $3.2 \mathrm{~mW} / \mathrm{m}^{2}$. Note that a linear scaling of their forcing to the Marquart et al. (2003) contrail cover gives an RF that is roughly $17 \%$ higher than the Marquart et al. (2003) value, although both studies used the same model. This shows the limits of the linear scaling approach.

Omitting the diurnal cycle of air traffic in our calculations we derived a contrail radiative forcing of $2.4 \mathrm{~mW} / \mathrm{m}^{2}$. Scaling this value linearly for a contrail coverage of $0.047 \%$ or $0.06 \%$ results in forcings of $2.8 \mathrm{~mW} / \mathrm{m}^{2}$ and $3.6 \mathrm{~mW} / \mathrm{m}^{2}$, respectively. Given the very different approaches to calculating contrail cover and differences in the radiation code as well as taking into account the consequences of assuming a globally and seasonally fixed contrail optical depth, our values agree very well with those of the two earlier studies. Additionally, taking into account the differences in the studies' approaches to determining contrail cover, the agreement in the amount of global, annual mean contrail cover is remarkably good.

Our study agrees with the finding of Marquart et al. (2003), that global mean contrail radiative forcing is increased when the diurnal variation of air traffic/contrail cover is neglected. Including the diurnal cycle in their GCM simulation, Marquart et al. (2003) found global annual mean forcing to decrease by less than $10 \%$. However, we found that neglecting the diurnal variation of air traffic results in an overestimation of the global mean contrail radiative forcing by $20 \%$ (all sky) to $30 \%$ (clear sky). Given the rather different result with respect to the relative importance of this effect we see the need for future work.

It is important to note that global estimates of contrail radiative forcing crucially rely on calibrating their contrail 
coverage with observations. Unfortunately, the Bakan et al. (1994) study, which gives an area-mean contrail cover for the air traffic dense region of the eastern-Atlantic/westernEurope, and which is widely used to scale modeled contrail cover (e.g., Marquart et al., 2003; Fichter et al., 2005), has so far not been updated. Therefore, although we used flight data for 2002, our estimate of contrail radiative forcing is effectively for the year 1992. Estimates of contrail RF for other years (e.g., Sausen et al., 2005) can be obtained by linear scaling with the respective fuel usage. However, this method clearly has its limitations and there remain serious uncertainties. We therefore see an urgent need for an update of the Bakan et al. (1994) contrail cover values. Additionally it is highly desirable to have multi-year analyses of contrail cover over other regions of the globe.

Limitations of scaling with fuel usage notwithstanding, it is important to place our results in the context of previous studies, in order to understand why and how studies in the past have obtained radiative forcing numbers different to ours. For Table 7 we have compiled $R F$ numbers from previous studies for different time horizons and different contrail optical depths.

A linear scaling of our 1992 forcing value (fuel usage in 1992: $112 \mathrm{Tg} /$ year; IPCC, 1999) with fuel usage for the year 2000 ( $152 \mathrm{Tg}$ /year; TRADEOFF value for fuel usage by civil aviation; Gauss et al., 2006) gives a forcing of $2.7 \mathrm{~mW} / \mathrm{m}^{2}$ (Table 7). The TRADEOFF best estimate of radiative forcing from linear contrails in 2000 is $10 \mathrm{~mW} / \mathrm{m}^{2}$, based on scaled values from MS2001 $\left(15 \mathrm{~mW} / \mathrm{m}^{2}\right)$ and Marquart et al. (2003; $6 \mathrm{~mW} / \mathrm{m}^{2}$ ). Marquart et al. (2003) omitted the diurnal cycle in air traffic but used a variable contrail optical depth, with a global mean value of about 0.1 . A rough estimate of the effect of including differences in the diurnal cycle of air traffic leaves our estimate about a factor of 1.2 smaller than the scaled Marquart et al. (2003) estimate. Part of this discrepancy is most likely due to using a fixed contrail optical depth. An upscaling of our $\tau_{\mathrm{vis}}=0.3$ forcing $\left(5.0 \mathrm{~mW} / \mathrm{m}^{2}\right)$ for the year 2000 fuel usage gives a forcing of $6.8 \mathrm{~mW} / \mathrm{m}^{2}$, which is within the TRADEOFF range of estimates (Sausen et al., 2005).

Scaling with fuel usage in $2002(156 \mathrm{Tg} /$ year; Eyers et al., 2004) we obtain a forcing of $2.8 \mathrm{~mW} / \mathrm{m}^{2}$ for $\tau_{\mathrm{vis}}=0.1$ and $7.0 \mathrm{~mW} / \mathrm{m}^{2}$ for $\tau_{\mathrm{vis}}=0.3$. Taking into account the rather different approaches to the calculation of both contrail cover and contrail radiative forcing and especially our fixed optical depth, the estimate of annual mean, global mean contrail radiative forcing agrees reasonably well with other post-IPCC (1999) studies. This supports the conclusion by Sausen et al. (2005) that the IPCC estimate of radiative forcing due to line-shaped contrails was considerably too high.

Note that these radiative forcing numbers give an estimate of the effects due to line-shaped, persistent contrails only. They neither include the possible radiative effects of aged contrails, i.e., spread contrails that are no longer line-shaped. Nor do they include the effects of aviation induced cirrus clouds, i.e., the feedback between contrails and cirrus clouds due to additional ice water formation and the impacts of an accumulation of aircraft emitted aerosols on cirrus cloud coverage. Currently all these mechanisms are still too uncertain to provide for anything close to a reliable forcing estimate.

Acknowledgements. We wish to thank G. Rädel and K. Shine for valuable input during the course of this study and many stimulating discussions. C. Eyers made the AERO2k data available for us and A. Tompkins provided us with ECMWF analysis data. We thank the anonymous reviewers for their helpful comments and are very grateful for many thoughtful comments from M. Ponater and editor B. Kärcher. This study was funded by the UK Department for Transport.

Edited by: B. Kärcher

\section{References}

Bakan, S., Betancor, M., Gayler, V., and Grassl, H.: Contrail frequency over Europe from NOAA-satellite images, Ann. Geophys., 12, 962-968, 1994,

http://www.ann-geophys.net/12/962/1994/.

Carlin, B., Fu, Q., Lohmann, U., Comstock, J. M., Mace, G. G., and Sassen, K.: High cloud horizontal inhomogeneity and solar albedo bias, J. Climate, 15, 2321-2339, 2002.

Charlock, T. P., Rutan, D., Smith, G. L., et al.: Clouds and the Earth's Radiant Energy System (CERES) Algorithm Theoretical Basis Document, NASA Reference Publ. 1376, vol. IV., 1995.

Duda, D. P., Minnis, P., and Nguyen, L.: Estimates of cloud radiative forcing in contrail clusters using GOES imagery, J. Geophys. Res., 106, 4927-4937, 2001.

Edwards, J. M. and Slingo, A.: Studies with a flexible new radiation code. I: Choosing a configuration for a large-scale model, Quart. J. Roy. Meteorol. Soc., 122, 689-719, 1996.

Ellingson, R. G. and Fouquart, Y.: Intercomparison of radiation codes in climate models, ICRCCM, WCRP-39, WMO/TD-371, 1990.

Eyers, C. J., Norman, P., Middel, J., Plohr, M., Michot, S., Atkinson, K., and Christou, R. A.: AERO2k Global Aviation Emissions Inventories for 2002 and 2025 (available from QinetiQ Ltd, Cody Technology Park, Farnborough, Hampshire, GU14 0LX, UK), 2004.

Fichter, C., Marquart, S., Sausen, R., and Lee, D. S.: The impact of cruise altitude on contrails and related radiative forcing, Meteorol. Zeitschrift, 14, 563-572, doi:10.1127/09412948/2005/0048, 2005.

Forster, P. M. de F., Shine, K. P., and Stuber, N.: It is premature to include non- $\mathrm{CO}_{2}$ effects of aviation in emission trading schemes, Atmos. Environ., 40, 1117-1121, doi:10.1016/j.atmosenv.2005.11.005, 2006.

$\mathrm{Fu}, \mathrm{Q}$.: An accurate parameterization of the solar radiative properties of cirrus clouds for climate models, J. Climate, 9, 20582082, 1996.

Fu, Q. and Liou, K. N.: On the correlated k-distribution method for radiative transfer in nonhomogeneous atmospheres, J. Atmos. Sci., 49, 2139-2156, 1992.

$\mathrm{Fu}$, Q. and Liou, K. N.: Parameterization of the radiative properties of cirrus clouds, J. Atmos. Sci., 50, 2008-2025, 1993. 
Fu, Q., Liou, K. N., Cribb, M. C., Charlock, T. P., and Grossman, A.: Multiple scattering parameterization in thermal infrared radiative transfer, J. Atmos. Sci., 54, 2799-2812, 1997.

Fu, Q., Yang, P., and Sun, W. B.: An accurate parameterization of the infrared radiative properties of cirrus clouds for climate models, J. Climate, 11, 2223-2237, 1998.

Gauss, M., Isaksen, I. S. A., Lee, D. S., and Søvde, O. A.: Impact of aircraft $\mathrm{NO}_{\mathrm{x}}$ emissions on the atmosphere - tradeoffs to reduce the impact, Atmos. Chem. Phys., 6, 1529-1548, 2006,

http://www.atmos-chem-phys.net/6/1529/2006/.

Gierens, K. M.: Numerical simulations of persistent contrails, J. Atmos. Sci., 53, 3333-3348, 1996.

Gounou, A. and Hogan, R. J.: A sensitivity study of the effect of horizontal photon transport on the radiative forcing of contrails, J. Atmos. Sci., 64, 1706-1716, 2007.

IPCC: Aviation and the Global Atmosphere - A Special Report of IPCC Working Groups I and III, edited by: Penner, J. E., Lister, D. H., Griggs, D. J., et al., Cambridge Univ. Press, Cambridge, UK, 1999.

Kley, D., Russell III, J. M., Gettelman, A., et al.: SPARC Assessment of Upper Tropospheric and Stratospheric Water Vapour, WCRP-113, WMO/TD-No. 1043 (SPARC, Verrieres le Buisson Cedex), 2000.

Marquart, S.: Climate impact of contrails: Investigations by means of an atmospheric general circulation model, DLR Forschungsbericht 2003-16 (published in German), Cologne, Germany, 161 pp, 2003.

Marquart, S. and Mayer, B.: Towards a reliable GCM estimation of contrail radiative forcing, Geophys. Res. Lett., 29(8), 20-1-20-4, doi:10.1029/2001GL014075, 2002.

Marquart, S., Ponater, M., Mager, F., and Sausen, R.: Future development of contrail cover, optical depth and radiative forcing: Impacts of increasing air traffic and climate change, J. Climate, 16, 2890-2904, 2003.

Meerkötter, R., Schumann, U., Doelling, D. R., Minnis, P., Nakajima, T., and Tsushima, Y: Radiative forcing by contrails, Ann. Geophys., 17, 1080-1094, 1999, http://www.ann-geophys.net/17/1080/1999/.

Meyer, R., Mannstein, H., Meerkötter, R., Schumann, U., and Wendling, P.: Regional radiative forcing by line-shaped contrails derived from satellite data, J. Geophys. Res., 107(D10), ACL 171-ACL 17-15, doi:10.1029/2001JD000426, 2002.
Minnis, P., Schumann, U., Doelling, D. R., Gierens, K. M., and Fahey, D. W.: Global distribution of contrail radiative forcing, Geophys. Res. Lett., 26, 1853-1856, 1999.

Myhre, G. and Stordal, F.: On the tradeoff of the solar and thermal infrared radiative impact of contrails, Geophys. Res. Lett., 28, 3119-3122, 2001.

Ponater, M., Marquart, S., and Sausen, R.: Contrails in a comprehensive global climate model: Parameterization and radiative forcing results, J. Geophys. Res., 107(D13), ACL 2-1-ACL 2-15, doi:10.1029/2001JD000429, 2002.

Rossow, W. B., Garder, L., Lu, P.-J., and Walker, A.: International Satellite Cloud Climatology Project (ISCCP) Documentation of Cloud Data, WMO/TD 266, World Climate Research Programme, Geneva, 1988.

Sausen, R., Gierens, K., Ponater, M., and Schumann, U.: A diagnostic study of the global distribution of contrails part I: Present day climate, Theor. Appl. Climatol., 61, 127-141, 1998.

Sausen, R., Isaksen, I., Hauglustaine, D., Grewe, V., Lee, D. S., Myhre, G., Köhler, M. O., Pitari, G., Schumann, U., Stordal, F., and Zerefos, C.: Aviation radiative forcing in 2000: An update on IPCC (1999), Meteorol. Zeitschrift, 14, 555-561, doi:10.1127/0941-2948/2005/0049, 2005.

Schmitt, A. and Brunner, B.: Emissions from aviation and their development over time, DLR-Mitt. 97-04, Deutsches Zentrum für Luft- und Raumfahrt e.V., Köln, Germany, pp. 37-52, 1997.

Schumann, U.: On the effect of emissions from aircraft engines on the state of the atmosphere, Ann. Geophys., 12, 365-384, 1994, http://www.ann-geophys.net/12/365/1994/.

Strauss, B., Meerkötter, R., Wissinger, B., Wendling, P., and Hess, M.: On the regional climatic impact of contrails: microphysical and radiative properties of contrails and natural cirrus clouds, Ann. Geophys., 15, 1457-1467, 1997, http://www.ann-geophys.net/15/1457/1997/.

Stuber, N., Forster, P., Rädel, G., and Shine, K.: The importance of the diurnal and annual cycle of air traffic for contrail radiative forcing, Nature, 441, 864-867, doi:10.1038/nature04877, 2006.

Tompkins, A. M., Gierens, K., and Rädel, G.: Ice supersaturation in the ECMWF integrated forecast system, Quart. J. Roy. Meteorol. Soc., 133, 53-63, 2007. 